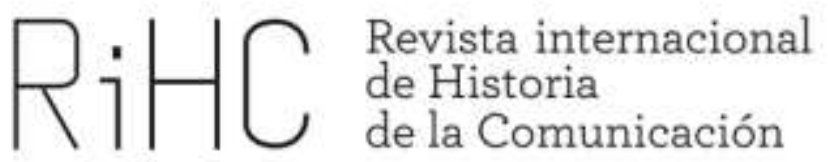

\title{
EL CAMPO Y LA PRENSA ESPECIALIZADA: EL ESTUDIO DE SU DESARROLLO $Y$ CONSOLIDACIÓN A TRAVÉS DE LA CONTRIBUCIÓN INDUSTRIAL
}

DOI: http://dx.doi.org/10.12795/RiHC.2016.i07.01

Ainhoa Gilarranz Ibáñez

Universidad Autónoma de Madrid

ainhoa.gilarranz@uam.es

Recibido: 18-9-2016

Aceptado: 20-11-2016

Resumen: El objetivo de esta comunicación es el análisis la publicación especializada "El Campo" tanto a nivel social como económico. Por un lado, se trata de estudiar el contenido de esta cabecera, una de las primeras especializadas en el sport, en relación al desarrollo del ocio a finales del XIX. Por otro lado, con el deseo de ampliar el conocimiento sobre el ámbito empresarial y económico se analizan los archivos de la Contribución Industrial, tanto de El Campo como de otras publicaciones especializadas con el objetivo de comparar su evolución y consolidación en el mercado periodístico de finales del XIX.

Palabras clave: El Campo, Contribución Industrial, prensa especializada, siglo XIX

Abstract: The aim of this paper is study in a socially and economically level the newspaper El Campo. The first part is focus in the news of this publication into a space 
in which began the leisure between the population. In the second part, we analyse the documents of the Industrial Contribution to increase knowledge in the areas of diffusion, economics and business origin of nineteenth-century press. The objective is compare development and strengthening of El Campo in journal market of the last decades of nineteenth century.

Keywords: El Campo, Industrial Contribution, specialized press, nineteenth century.

\section{El ocio y la prensa especializada en el divertimento}

En 1786 el Supremo Consejo de Castilla deseaba reformar el reglamento vinculado a los espectáculos y antes de desarrollar la normativa mandó a la Real Academia de la Historia elaborar un informe sobre el origen y la evolución de los distintos juegos, exhibiciones y diversiones públicas de cada una de las provincias españolas. El estudio recayó en manos de Gaspar Melchor de Jovellanos que en 1790 entregó su Memoria para el arreglo de la policía de los espectáculos y diversiones públicas y sobre su origen en España a la Institución que se lo había encargado. Entre una de las conclusiones, el intelectual recalcaba:

...las clases pudientes, que viven de lo suyo, que huelgan todos los días o que al menos destinan alguna parte de ellos a la recreación y al ocio, difícilmente podrán pasar sin espectáculos, singularmente en grandes poblaciones. En las pequeñas, compuestas por la mayor parte de agricultores, podrá haber poca diferencia en las costumbres de sus clases. Cada una tiene sus cuidados y pensiones diarias. Los propietarios y colonos, granjeros y asalariados, todos trabajan de un modo o de otro, y si en los ricos son menos necesarias las tareas de fatiga, también el destino de mayor parte de tiempo al sueño, a la comida y al descanso, o cuando no a la caza, la conversación, el juego y la lectura llenan los espacios del día e igualan muy exactamente la condición de unos y otros... (JOVELLANOS, 1790: sin p.)

Jovellanos apreciaba en su memoria la diferencia que encontraba entre las actividades de ocio de unos grupos sociales y otros; divertimento había en todas las clases, pero en función del estamento social se derivaban a unas actuaciones o a otras. Esta separación fue ampliándose durante todo el siglo XVIII cuando la mercantilización del ocio se estableció entre la sociedad europea. Investigadores como John Harold Plumb o Robert W. Malcolmson ${ }^{1}$ concluyen en sus estudios como desde 1700 hasta las

\footnotetext{
${ }^{1}$ Algunos ejemplos de estos estudios son: MALCOLMSON, R.W (1973): Popular Recreations in English Society 1700-1850, Nueva York, Cambridge University Press; PLUMB, J.H (2001): "La mercantilización del ocio en la Inglaterra del siglo XVIII", en Historia Social, no41, 2001, pp.69-88.
} 
primeras décadas del XIX se desarrolló la estructura comercial del divertimento. Unos estudios cuyo desarrollo tuvo su origen en otras corrientes historiográficas como la historia del deporte, la historia de costumbres o la importante línea de investigación sobre el folkclore desarrollada en Reino Unido (URIA GONZÁLEZ, 2001: 66). Estos trabajos sociológicos permiten al historiador observar las diferencias existentes entre varios grupos sociales, u observar la evolución de un mismo conjunto a lo largo de los siglos. Es el siglo XIX especialmente interesante, la época contemporánea fue el momento en el que las prácticas ociosas de la aristocracia fueron reconvertidas para la sociedad burguesa como un espacio de creación en el que agentes sociales fomentan o retraen dinámicas soailes (URÍA GONZÁLEZ, 2001: 89). La Revolución Industrial aceleró la comercialización del ocio y convirtió este espacio de recreo en una categorización social muy significativa. El consumo de las actividades culturales como el teatro, los bailes y los toros, se vio reflejada en una mayor demanda de prensa especializada en esas áreas de divertimento. La población exigía más noticias de las que aparecían en la prensa general y así surgieron las cabeceras dedicadas a un área concreta de conocimiento: ciencias, literatura, arte, etc. En este camino hacia la especialización informativa fueron las noticias sobre deporte o tauromaquia las primeras que contaron con una sección concreta en las cabeceras de información general (SÁNCHEZ VIGIL, 2008: 190).

Para conocer en profundidad la vida e importancia de cada una de las publicaciones especializadas en el área del ocio, el investigador puede ayudarse de datos concretos que nos ofrecen los archivos especializados en comercio y economía mercantil. Una de las principales complejidades de la prensa decimonónica radica en la dificultad de realizar un seguimiento de sus cabeceras; los títulos aparecían y desaparecían continuamente, cambiaban de nombre o de dueño. Gracias a los datos que ofrecen documentos económicos como los registros de la Contribución Industrial, el investigador puede elaborar la línea de la vida de una publicación y realizar una comparativa con otras cabeceras de similares características.

La elaboración de este estudio parte de esas dificultades existentes al usar la prensa como fuente histórica ya mencionadas por Robert Marrast, quién consideraba las publicaciones como un objeto que debe estudiarse desde la perspectiva autónoma y compleja. Por una parte, internamente en función a su relación con otras publicaciones, pero también en vinculación con su público y el grupo social entre el que circulaba (MARRAST, 1975: 16-17). Este texto tiene el objetivo de abordar la empresa periodística especializada desde el contenido y el continente, es decir, desde aquello que se publica hasta cómo se publica. De esta manera, se puede realizar un análisis completo de una publicación periódica; no sólo se tiene en cuenta la información que hay dentro de sus páginas, sino que también se tiene presente el papel que cumple esa revista en el mundo de la comunicación. El objetivo de este trabajo en definitiva es analizar en profundidad la cabecera El Campo: agricultura, 
jardinería y sport y compararla con otras cabeceras de similares características. Finalmente, con los datos obtenidos se podrá vislumbrar un fragmento del mapeado empresarial y económico generado alrededor de la prensa especializada decimonónica.

\section{El Campo: la revista del sport decimonónico}

El gran espacio dedicado al ocio apareció en la segunda mitad del XIX con la expansión de las revistas "ilustradas" aplicado a aquellas en las que la imagen tenía una importancia especial, tanto por su calidad como por la actualidad de las mismas (SÁNCHEZ VIGIL, 2008: 43). En estas revistas, la imagen era la protagonista y en muchas ocasiones al grabado se le otorgaba mayor importancia que a la información en texto; de ahí que normalmente, la ilustración más importante de cada número soliese ir colocada en las páginas centrales e incluso formasen coleccionables que recopilaban sus lectores. Aunque la revista ilustrada fuese de información general como en La Ilustración Española y Americana, habitualmente se destinaba un espacio al divertimento. Las veladas teatrales o las salidas a la ópera se relataban brevemente en las secciones como "Noticias sociales" o "Sociedad" mientras que su representación iconográfica ocupaba mayor espacio en la publicación.

El deporte se convirtió en uno de los protagonistas de las revistas ilustradas. Desde mediados del siglo XIX el interés por la información deportiva fue en aumento. Las primeras publicaciones dedicadas a esta área surgieron en Reino Unido y Francia; Sportman publicado en Londres a partir de 1852 se considera la primera revista dedicada al deporte. Dos años después, la capital francesa contaba con otra publicación de similares características, Le Sport, fundado por Eugene Chapaux en 1854 (SAINZ DE BARANDA ANDÚJAR, 2013: 8-9). Ambos países eran la referencia para España, y así en 1877 surgió El Sport Español. Desde mediados del siglo XIX, el interés de la aristocracia y la alta burguesía española sobre las actividades que englobaban este concepto proveniente de Inglaterra aumentaron considerablemente. Las altas esferas españolas venían observado desde el siglo XVIII como ingleses y franceses gastaban su tiempo libre con actividades físicas como carreras de caballos, tenis o regatas de las que se disfrutaba al aire libre ofreciendo la opción de relacionarse socialmente lejos del ambiente urbanita.

La publicación gaditana El Sport Español fue la primera en dedicarse al completo a la información deportiva, sin embargo entre las primeras cabeceras que se registraron con la palabra británica encontramos dos publicaciones madrileñas: la Gaceta del Sport 
(1873) y El Campo: agricultura, jardinería y sport. De la primera no se han encontrado colecciones, sin embargo los ejemplares de la segunda componen parte del fondo periodístico de la Biblioteca Nacional.

A pesar de ser inscrita con el subtítulo de "agricultura, jardinería y sport", lo cierto es que en su cabecera no apareció esa tercera especialidad textualmente sino mediante una ilustración. Su primer número se publicó en diciembre de 1876 quedando establecida entre la prensa de la época como la revista en la que se difundía todo lo relacionado con el deporte de las esferas privilegiadas:

EL CAMPO, revista quincenal de Agricultura y jardinería, según modestamente se Ilama; pero que abraza y trata de otras materias no menos importantes. Nada se echa de menos en sus columnas; ni estudios profundos y eruditos sobre faenas agrícolas, botánica é historia natural; ni novelas firmadas por D. Juan Valera y otros literatos eminentes (...) EL CAMPO es además el periódico oficial del sport español, pues da cuenta de las carreras que se celebran en las provincias; de los resultados de tiro de pichon [sic.] (...) Enviemos al Sr. Albareda, su fundador y propietario, y al conde de las Cinco Torres, su director, el sincero testimonio de nuestra aprobación y nuestro aplauso, deseándoles que su generosa tentativa sea coronada por éxito completo (La Época, 23-5-1878)

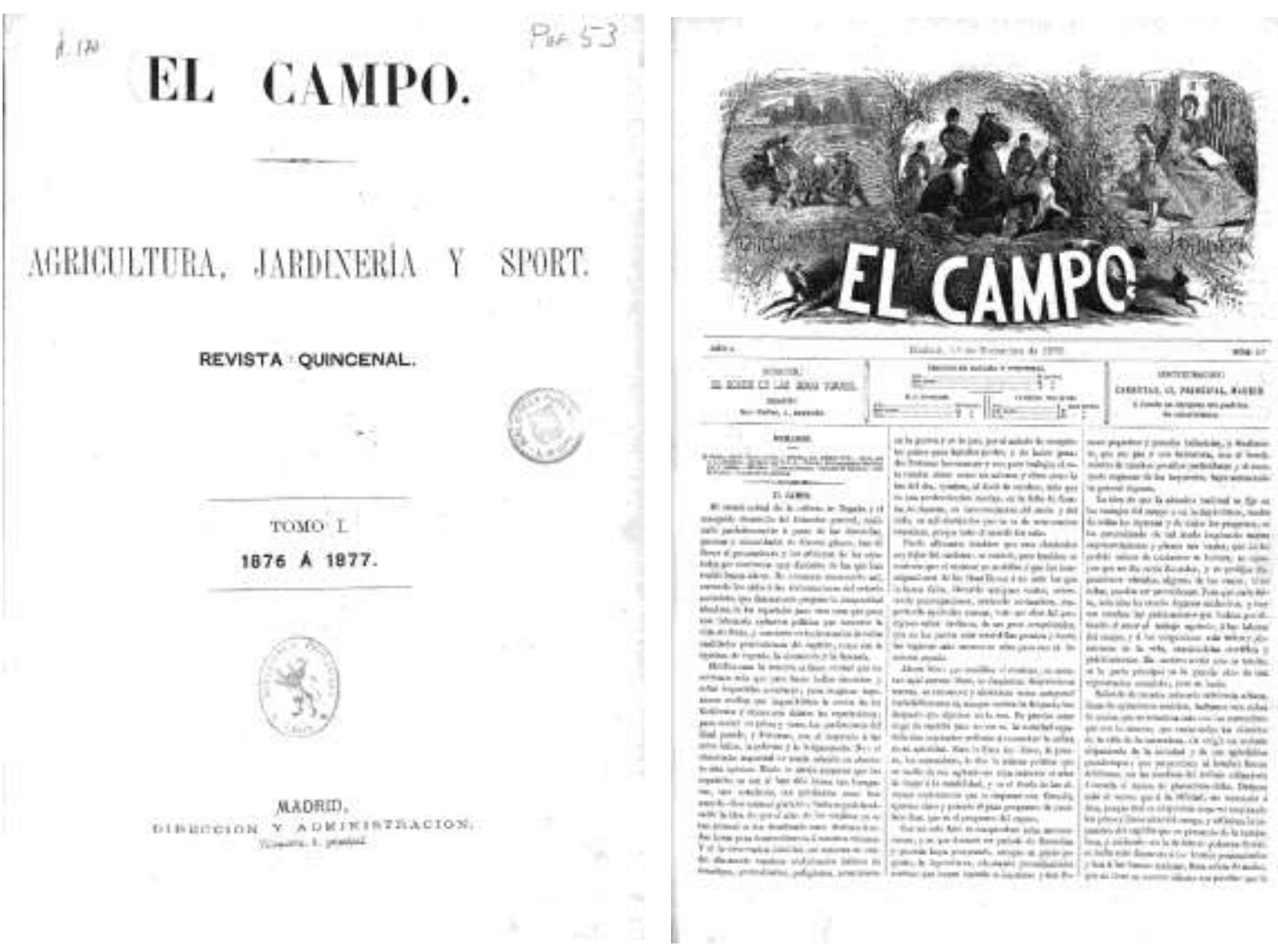


La publicación quedaba bajo la dirección del Conde de las Cinco Torres aunque la propiedad era de José Luis Albareda y Abelardo de Carlos, hasta noviembre de 1877 momento en el que sólo quedaba bajo la pertenencia del primero. Ambos propietarios eran populares figuras del mundo periodístico; el primero, periodista y fundador de $L a$ Revista de España de corte político-intelectual, llegó a convertirse en Ministro de Fomento (1881-1883) y de la Gobernación (1887-1888); por su parte, Abelardo de Carlos era el dueño de otras dos importantes cabeceras periodísticas: La llustración Española y Americana y La Moda Elegante.

El Campo, de perioricidad quincenal, gozó de quince años de vida, su primer ejemplar apareció en diciembre de 1876 y el último en diciembre de $1892 .^{2}$ De dimensiones tabloides, el número de sus páginas fue en aumento de 14 a 16 a medida que sus suscriptores crecían, o así lo expresaron desde su redacción (El Campo, 01-12-1877). Se componía de una cabecera ilustrada que daba constancia de los principales temas que abordaba la publicación y de un conjunto de secciones fijas -"Caballos", "Noticias generales", "Noticias de sociedad", "Floricultura"- que se intercalaban con secciones temporales -“Caza", "Pesca", "Fisiología del Corral"- y otros espacios dedicados a las cartas de los lectores o anuncios publicitarios.

El sport destacaba dentro de El Campo por las amplias secciones que dedicaba a esta temática. Entre sus firmas se encontraban populares periodistas y novelistas como Juan Valera o Benito Pérez Galdós que en el primer número de la publicación esclarecía para los no entendidos el significado de la palabra inglesa:

Saliendo de nuestra rutinaria existencia urbana, llena de agitaciones estériles, hallamos una esfera de acción que se relaciona más con las costumbres que con la ciencia (...) esta esfera de acción, que no tiene en nuestro idioma voz peculiar que la caracterice, es lo que los ingleses llaman sport, un conjunto de nobles ejercicios y de ocupaciones entretenidas fuera de las ciudades... (PÉREZ GALDÓs, El Campo, 01-12-1876)

Si La llustración española y americana o La ilustración artística ofrecían espacios de riqueza y lujo en sus litografías dedicadas a las veladas en el Teatro Real, o en una tarde taurina; desde El Campo esos escenarios se trasladaron a las afueras de la ciudad, sin dejar de transmitir su carácter de exclusividad. Aunque la diversión se había trasladado al ámbito rural no desapareció su vínculo con el rol social. La clase no privilegiada podía también realizar estas actividades, pero desde la prensa la división era clara, creándose estereotipos sociales como el sportman.

\footnotetext{
2 Pueden consultarse varios ejemplares de esta cabecera en la Biblioteca Nacional de España. (http://datos.bne.es/edicion/bise0000037824.html) y en la hemeroteca municipal de Madrid. (http://catalogos.munimadrid.es/cgi-bin/hemeroteca/O7413/IDba44e3d5?ACC=161); los ejemplares comprendidos entre diciembre de 1876 y noviembre de 1881 se encuentran digitalizados en la Biblioteca Virtual de Prensa Histórica.

(http://prensahistorica.mcu.es/es/consulta/registro.cmd?id=3025).
} 
Las publics hauses se ven llenas; una multitud de estos tipos que se encuentran en Inglaterra en todas las carreras, que asisten a todas las reuniones sin tener con que comprarse una camisa, llenan la sala común, bebiendo cerveza, discutiendo ruidosamente sobre las reuniones pasadas y dando sus opiniones sobre las próximas. En los sitios de reunión de un orden mas elevado, los clubman y los miembros del Tattestall, con guantes y flores en el ojal de la levita, preparan sus baterías para las carreras de la semana, y se ven lores con fortunas de príncipes (...) el sport es para ellos un negocio gravo y no una distracción, van al sitio de las carreras como si fueran a la Bolsa (El Campo, 16-11-1877).

Si por un lado se creaban figuras sociales, por otra parte, se modificaron estereotipos ta existentes. En el caso de las mujeres, el interés por potenciar un aumento de lectoras se mantuvo a lo largo de toda la publicación manteniendose dentro de la tendencia del momento de revistas destinadas a la mujer burguesa (CAZOTTES y RUBIO CREMADES, 2012: s.p.). Artículos y grabados dedicados damas aristocráticas, como la duquesa de Huéscar, se entremezclaban con textos dedicados al género femenino -novela seriada "Mujeres del gran mundo" publicada en varios números de 1880, "La influencia de la mujer" (El Campo, 01-09-1881)-. De este modo, la imagen de la mujer se alejaba de la sociedad urbana para adentrarse a la vida rural y la hacía partícipe de sus actividades. La introducción de género femenino en este ámbito no produjo un cambio en el rol familiar, el "ángel del hogar" fue readaptado al modelo que la prensa femenína de la época difundía. Si la mujer de ciudad leía, cosía e iba a la ópera y al teatro, la dama de El Campo cabalgaba, jugaba al tenis y ofrecía su mayor atractivo al realizar actividades físicas al aire libre.

La hermosura de la mujer se presenta á la vista del hombre bajo múltiples formas é innumerables aspectos; su belleza no está sujeta a principios fijos, ni puede juzgarse por preconcebidas reglas; pero si el criterio de la razón hubiera de señalar la hora del triunfo de sus atractivos nosotros, al menos, no titubeamos en firmar que cuando más ostenta su hermosura es á caballo (...) la mirada seductora de la edad perfecta de la vida, y los acentos incisivos de todos los discretos sociales resultan pálidos ante la animación del rostro, ante el brillo de los ojos y el grito de entusiasmo que levantan el ánimo de la mujer en un día de caza á caballo... (El Campo, 16-01-1877)

En conjunto, la información que ofrecía en cada uno de sus números tenía como destino informar a las altas esferas sociales de los nuevos ocios que podían practicar. Ello se percibía en dos factores dentro de la revista: el primero, el estilo de las informaciones y litografías; y el segundo, en los espacios referentes a la recepción de la revista como las cartas al director y los anunciantes. La élite se encontraba reflejada tanto en los textos como en las imágenes publicadas. En consecuencia, las actividades populares eran descritas con desprecio y categorizadas como vulgares. De este 
mensaje se hizo eco El Campo al vincular las maravillas del aire libre tanto al carácter civilizador como al propio de la élite social:

En España los placeres del campo y las excursiones venatorias han sido exclusivamente ocupación predilecta de los grandes señores y poseedores de cotos, fincas, granjas y casas de recreo; la clase media ha mostrado siempre poca afición á apartarse del laberinto de las ciudades, y el pueblo, ávido de descanso, incapaz de comprender que éste consiste principalmente en la variación de la actividad, ha buscado un solaz pasajero en las soeces merendonas y borracheras de los domingos, tan deplorables para el alma como para el cuerpo... (PÉREZ GALDÓS, El Campo, 01-12-1876)

Además de ser la primera publicación que dedica una mención especial al sport, sin duda fueron sus grabados uno de sus elementos más llamativos. Desde su primer número utilizó la imagen como medio de difusión de un ideal social. Las litografías que publicaban reflejaban un mundo idílico en el que la actividad al aire libre se transmitía como un acto de nobleza y tradición. El espacio rural era reconstruido como si del paraíso se tratase con grabados de animales mansos, bellos parajes e ilustres castillos. Uno de cada dos ejemplares presentaba una litografía protagonizada por paisajes que ilustraban fincas, palacios o castillos propiedades de la aristocracia española y en ocasiones extranjera.

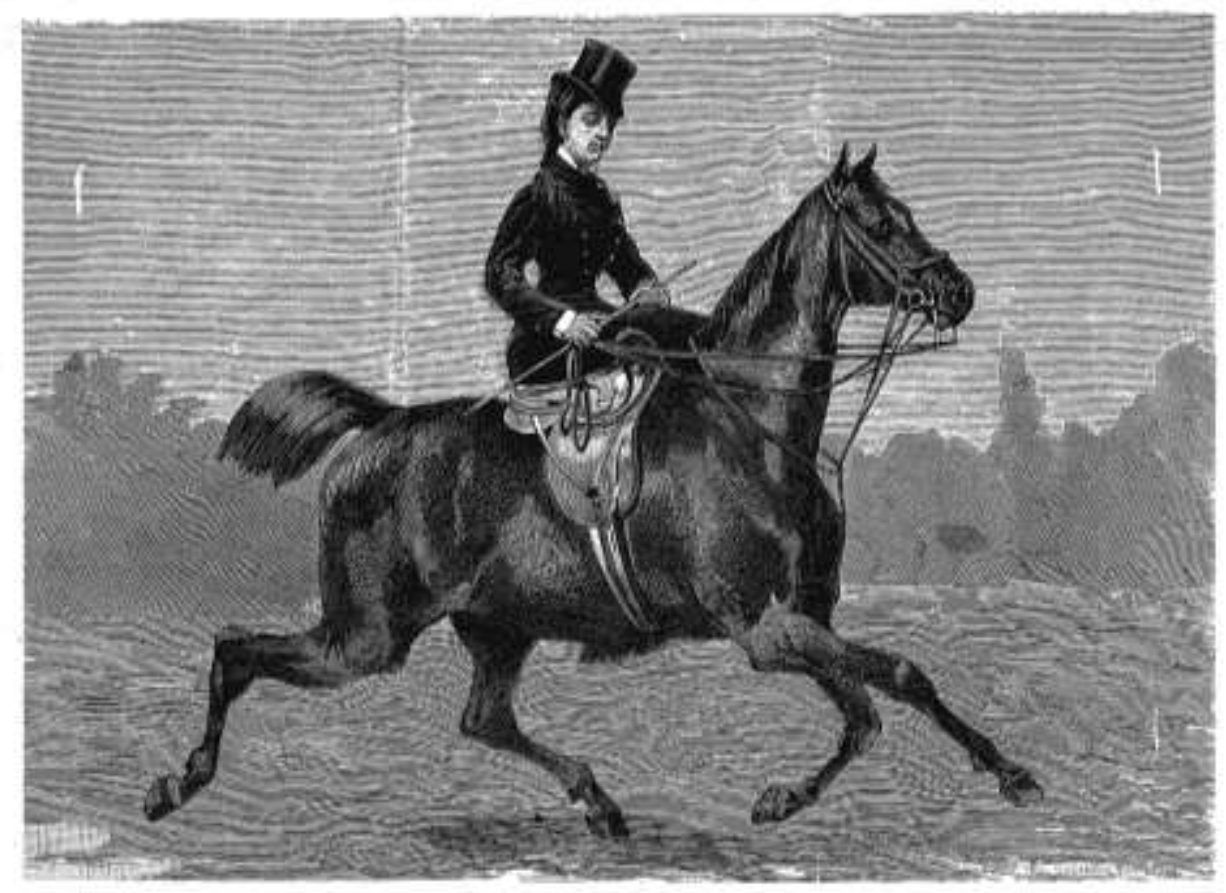

LA neveas newras be tetecsa. 


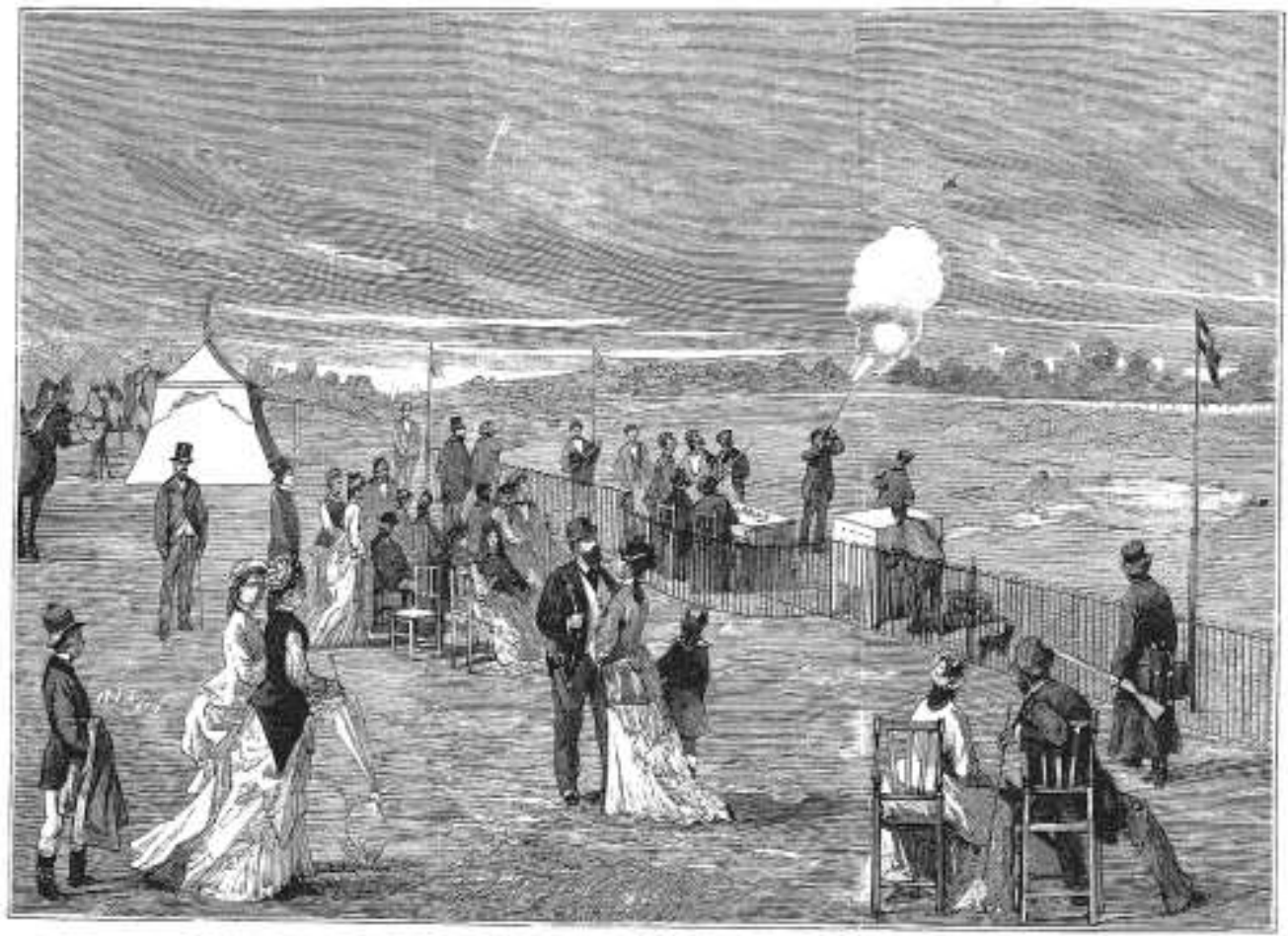

tho de vanos ye vasate.

Dos litografías publicadas en El Campo: agricultura, jardineria y sport. Superior: "La señora duquesa de Huéscar" (16/01/1879); Inferior: "Tiro de Pichón en Madrid” (01/01/1878).

Biblioteca Virtual de Prensa Histórica.

Este público tan selecto potenciaba que el mantenimiento de la cabecera se basara en las suscripciones $\mathrm{y}$ en un aumento del espacio dedicado a la publicidad. El mantenimiento por suscripción se entreveía en el carácter coleccionable de varias de sus secciones. En cuanto a la publicidad, si en sus primeros ejemplares el espacio dedicado a ello era apenas media página, desde finales de 1880 la sección "Anuncios" protagonizaba las dos últimas páginas de la cabecera.

\section{Los datos de la Contribución Industrial y otras fuentes para el estudio de la empresa periodística}

Fue el trabajo de Jean-François Botrel el primero en llamar la atención sobre la importancia de los archivos de la Contribución Industrial para estudiar la historia de la prensa. En resumidas cuentas, el registro de la Contribución Industrial es un impreso «repartido entre los distintos sectores del comercio y de la industria, divididos en diversas tarifas, y dentro de cada tarifa, en varias clases» (BOTREL, 1975: 25). Entre 
esas categorías hay un espacio dedicado a los editores de periódicos, y en su interior, un apartado subdividía las publicaciones en función de su género y periodicidad bajo la distinción: periódicos políticos diarios, semanales, bisemanales, periódicos científicos y periódicos de anuncios. La categorización de cada cabecera periodística era muy enriquecedora al aportar no sólo el nombre de la publicación y el de su director sino además información sobre los impresores, su nombre e incluso su domicilio.

El Gobernador Civil de cada provincia era quien realizaba la clasificación de las cabeceras dentro del registro, y atendiendo a la categoría en la que quedase registrado cada periódico así el coste de la cuota era mayor o menor. "Este impuesto venía a ser un arma contra la prensa de escasos recursos económicos, incapaz de efectuar tales desembolsos (...) Si por parte del Gobierno se quería acabar con algún periódico, que pudiera molestar ideológica y políticamente, no había más que exigirle el pago de dicho impuesto" (AGUADO, 1995: 63); de ahí que muchas cabeceras de las que se conoce su existencia en determinados años, bien porque eran citadas por otras fuentes periodísticas o bien porque a día de hoy tenemos ejemplares que han sobrevivido, no aparezcan dentro del listado de la Contribución Industrial.

La cautela es necesaria para abordar el estudio de la Contribución Industrial ya que los libros de cuentas no siempre nos ayudan dentro de nuestra investigación; más bien confunden la información y generan ruido debido al alto número de datos que debemos manejar por cada año económico. El problema se incrementa al no tener la metodología suficientemente desarrollada dentro de la historiografía para poder abordar este tipo de documentación. Otra puntualización a tener presente es la clasificación de las publicaciones, en ocasiones demasiado simple y problemática. La prensa se categorizó en publicaciones políticas y no políticas, diferenciación realizada en las principales estadísticas oficiales de las instituciones estatales, dando paso a esa simplicidad anunciada anteriormente y a un problema de identidad, pues ni los coetáneos se consensuaban sobre la orientación de los medios más populares (TIMOTEO ALVAREZ, 1981: 60). Esto se tradujo en los libros de la Contribución Industrial en la división de las cabeceras en dos grandes áreas: política y científicoliteraria; convirtiéndose esa segunda categoría en un cajón caótico en el que podía clasificarse todo tipo de publicaciónes.

A partir de 1875, el estudio de la prensa contará con dos apoyos: los Libros de Adiciones y las Bajas de la matrícula Industrial elaborados por el Ministerio de Hacienda. Estos dos documentos, unidos al Registro de la Contribución Industrial, permiten al historiador observar de principio a fin la vida de una cabecera periodística y completar las lagunas que cada documento a nivel individual podría tener. La existencia de estos documentos viene dada por la normativa aprobada con la llegada de la Restauración según la cual todo nuevo periódico necestaba obtener una licencia del Ministerio de la Gobernación, permiso que se obtenía si el jefe político provincial 
realizaba un informe favorable sobre la publicación (PIZARROSO QUINTERO, 1994: 282).

Siempre podremos añadir más datos a los que se desligan del registro de la Contribución Industrial. Por ejemplo, puede mezclarse su información con la que ofrecen los Anuarios del Instituto Nacional de Estadística; publicación que refleja de manera cuantitativa diversas áreas que componen la sociedad. En sus inicios, los anuarios no realizaban un estudio continuado y por lo tanto hay años en los que no tenemos datos, sin embargo para el periodo que engloba este estudio pueden citarse los anuarios de 1860-1861, y 1866-1867. ${ }^{3}$ Ambas publicaciones contabilizan dentro de su apartado "Estadística intelectual" las cabeceras periodísticas existentes a nivel provincial y por categorías: de modas, satírico-literarias, de noticias y avisos, de varias materias útiles y agradables, etc. Su análisis genera un conocimiento sobre el recorrido de la prensa durante la década de los 60 , justo antes de La Gloriosa que cambió la estructura periodística en España, e informan al historiador sobre la difusión de las publicaciones y su aglomeración en determinadas zonas geográficas y por áreas temáticas.

El papel de la publicidad es otro factor interesante en el estudio de la empresa periodística, un elemento que marca la evolución del sector hacia la profesionalización. Fue a partir de 1880 cuando los anuncios en prensa se consolidan como el factor para sostener a las cabeceras económicamente (HIGUERAS CASTAÑERA, 2014: 43). EI desarrollo publicitario influyó en una cada vez mayor independencia del periodismo de aquellos organismos que tradicionalmente lo sostenían para evolucionar hacia un periodismo empresarial.

\section{Estudio del caso: El Campo y sus vínculos con otras cabeceras especializadas}

Ahora ha llegado el momento de llevar a la práctica el uso de esos archivos para el estudio de la cultura periodística en la España del XIX pero antes veo necesaria una aproximación al mundo periodístico en las fechas en las que El Campo publicaba sus ejemplares. Fue desde 1858 hasta la ley de prensa promulgada en 1883, cuando el desarrollo periodístico en España se mantuvo ligado a los momentos de mayor o menor represión legislativa. Tras la explosión periodística de La Gloriosa gracias a la libertad de prensa, el fin de la Primera República y el inicio de la Restauración significó un estancamiento en el mundo periodístico debido a la aprobación de los decretos de

\footnotetext{
${ }^{3}$ Ambas publicaciones pueden consultarse en el fondo documental digitalizado por el Instituto Nacional de Estadística (http://www.ine.es/inebaseweb/25687.do).
} 
diciembre de 1874 y enero de 1875 que limitaban el ejercicio de la prensa. Sin embargo, desde 1879 la eliminación de la licencia previa para poner en marcha una publicación y la posterior ley de prensa de 1883, cambió el panorama que se caracterizó por un lado en la facilidad de iniciar nuevos proyectos periodísticos, pero por otro, en la alta mortalidad de las cabeceras a causa de la fragilidad económica (BOTREL, 1993: 367).

El Campo quedó inscrito por vez primera dentro de los archivos de la Contribución Industrial en el Libro de Adicciones [sic.] que comprendía los años 1876-1877. Catalogado dentro "Periódicos científicos" compartía espacio con otra nueva publicación que llegaba a las calles: El Globo, fundado por Emilio Castelar en marzo de 1875 y considerado uno de los primeros en incorporar asiduamente grabados entre sus páginas. Es curiosa la categorización similar de ambas cabeceras cuando su carácter era totalmente distinto; si El Campo era una publicación que podía comprenderse dentro de la prensa especializada en el deporte y el ocio, el periódico dirigido por el expresidente de la primera república española se caracterizaba por su información política y de estilo partidista que alcazó una gran difusión y popularidad no sólo entre los defensores del posibilismo de Castelar (SEOANE, 1983: 285-316). El desconocimiento sobre el estilo de información de cada nueva publicación registrada provocaba que muchas de ellas fueran catalogadas dentro de prensa científica, en donde entraba todo lo que no era prensa informativa; pero con la publicación de los números en las siguientes semanas podía darse la modificación categórica de las cabeceras y eso fue lo que le ocurrió a El Globo, que pasó de ser indexado dentro de la prensa científica ser catalogado dentro de la prensa política en los siguientes libros de la Contribución Industrial.

Dentro de estos libros se anotaba el nombre con el que se inscribía la nueva cabecera y el propietario de la misma, además de quedar fijado la cuota que debía pagar su dueño anualmente para que la cabecera pudiese publicarse. Estos datos son confusos pues cada cabecera tiene una cuota distinta a pesar de pertenecer a una misma categoría. Comparativamente, queda patente que los periódicos inventariados como "periódicos políticos diarios" tenían una cuota mayor que los incluidos en "periódicos políticos semanales" y "periódicos científicos"; sin embargo, incluso dentro de una misma categoría cada publicación pagaba una cuota desigual.

Para esclarecer los datos que ofrece la Contribución Industrial, equiparemos las publicaciones propiedad de Abelardo de Carlos que se encuentran todas inscritas en la categoría de "periódicos científicos"; además de haber sido seleccionadas por ser del mismo dueño, también se ha prestado atención a su tiempo de vida para poder 
realizar un seguimiento de todas ellas de aproximadamente una década. El primer libro de la Contribución Industrial que agrupa estas cabeceras fue el de 1878-18794:

\begin{tabular}{lllll} 
Propietario & Cabecera & Domicilio & $\begin{array}{l}\text { Cuota } \\
\text { (pts.) }\end{array}$ & $\begin{array}{l}\text { No } \\
\text { Matrícula }\end{array}$ \\
\hline Abelardo de Carlos & La Moda Elegante & Carretas 12 & 111,30 & 9214 \\
Abelardo de Carlos & La llustración Española & Carretas 12 & 111,30 & 9237 \\
& y Americana & & & \\
Abelardo de Carlos & El Campo & Carretas 12 & 59,36 & 9264
\end{tabular}

Datos obtenidos del libro 9047 de registro de la Contribución Industrial, Fondo 1, Ministerio de Hacienda, AGA. Elaboración propia.

Pese a que las tres revistas se encontraban en mismo ámbito, pertenecían al mismo propietario y tenían la misma domiciliación, sus cuotas anuales eran desiguales ¿A qué se debía? Podríamos encontrar una explicación al comparar las características propias de cada cabecera: periodicidad, número de páginas, precio por ejemplar, etc. Así se podría comprender como La Moda Elegante y La Ilustración Española y Americana pagaban una cuota mayor por ser publicadas semanalmente, al contrario que El Campo, de periodicidad bisemanal. La periodicidad debía de ser la que establecía la cuota pues si nos centramos en el número de páginas o en el precio de la suscripción La Ilustración Española y Americana y El Campo tienen mayor similitud.

$\begin{array}{lllll}\text { Cabecera } & \text { Periodicidad } & \begin{array}{l}\text { Suscripción } \\ \text { trimestral }\end{array} & \begin{array}{l}\text { Suscripción } \\ \text { mensual }\end{array} & \begin{array}{l}\text { № páginas } \\ \text { ejemplar }\end{array} \\ & & \begin{array}{l}\text { (pts) } \\ \text { (pts) }\end{array} & \\ \text { La Moda Elegante } & \text { Semanal } & 4,5 & 1,50 & 9 \\ \text { La llustración Española } & \text { Semanal } & 10 & 3,3 & 15-25 \\ \text { y Americana } & & & & 16 \\ \text { El Campo } & \text { Bisemanal } & 6 & 2 & \end{array}$

Relación de las publicaciones en función de su periodicidad, suscripción y número de páginas.

\footnotetext{
${ }^{4}$ Los libros de Contribución Industrial forman parte del fondo 1 del Archivo General de la Administración (AGA) referentes al Ministerio de Hacienda. Se detallará al final del artículo los libros analizados en función del año al que corresponden.
} 
Los datos rescatados de la Contribución dan acceso al investigador a la vida natural de una publicación y engloban los primeros pasos para descifrar la creación de una cultura de masas a través de su nivel empresarial. En el caso de El Campo, los datos de la Contribución Industrial ofrecen: su origen, su evolución a lo largo de la década de los 80 , cómo se consolida dentro de la prensa especializada junto los otros títulos de Abelardo de Carlos, y finalmente su cierre en 1892 al quedar indicado en una anotación del libro de de Contribución Industrial de dicho año.

Estas tres cabeceras compartieron categoría y se mantuvieron dentro del pódium de la cuota más alta a pagar anualmente. Dentro de la prensa científica se encontraban revistas especializadas en otras áreas temáticas como literatura y humor. La prensa joco-seria también tiene un papel importante dentro de la Contribución Industrial, pues estos archivos permiten indagar en la aparición y desaparición de las publicaciones satíricas gracias a que dejan constancia de sus cambios de nombre o de propiedad para evitar la censura. Hay una evolución dentro de las revistas humorísticas desde su gran eclosión a partir de 1868 y durante la Restauración; en los inicios de La Gloriosa fueron muchas las publicaciones satíricas que aparecieron pero tan rápido como se creaban también se volatilizaban, sin embargo desde finales de la década de los 70 se complementan las cabeceras de humor político, con otras publicaciones cómicas de un «periodismo festivo, amable y sin acidez» (SEOANE, 1983: 311) representado en cabeceras como Mundo cómico o Madrid cómico, esta última dirigida por Sinesio Delgado causante de que en ninguno de los números se hiciese eco de temas políticos y de tendencia antimodernista.

Dentro de los trabajos historiográficos dedicados a la historia de la prensa, las publicaciones satíricas han captado la atención de varios historiadores y hay publicadas varias monografías dedicadas a esta clase de cabeceras ${ }^{5}$. Más complicado es encontrar artículos o investigaciones especializadas en la prensa de ocio del XIX; sin embargo, la comparativa entre unas $\mathrm{u}$ otras posibilita una reflexión sobre el mercado de los medios de comunicación a finales del XIX y el interés del público entre una y otra tipología de revista.

Se ha querido poner en marcha un pequeño experimento en base a esta equiparación de cabeceras satíricas, de ocio y de temática especializada como la moda. Por supuesto, sus resultados no deben ser tomados como referencia para generalizar

\footnotetext{
${ }^{5}$ Entre los principales estudios sobre el género satírico pueden citarse: BORDERÍA, E. y MARTíNEZ GALLETO, F. (2010): La risa periodística. Teoría, metodología e investigación en comunicaión satírica, Tirant lo Blanch, Valencia.; DOMINGO, J. y MORENO, T. (1991): 150 años de prensa satírica española, Madrid, Ayuntamiento de Madrid; LLERA RUIZ, J. A. (2003): “Una historia abreviada de la prensa satírica en España: desde 'El Duende Crítico de Madrid' hasta 'Gedeón', en Estudios sobre el mensaje periodístico, no.9, pp. 203-214; GARRIDO CONDE, M.T. (1999): La prensa satírica en Sevilla durante el siglo XIX: estudio monográfico del periódico 'EI Tio Clarín', tesis doctoral dirigida por Ángel Benito Jaén, Universidad Complutense de Madrid; SANTAMARÍA LÓPEZ, J. M. (1996): “El humor en la prensa segoviana del siglo XIX", en Estudios segovianos, no.94, pp. 695-731.
} 
sobre la historia de la prensa de finales de siglo, pero si pueden guiarnos hacia nuevas pistas que profundicen en la empresa periodística y su desarrollo a lo largo del XIX. Para ello, se ha buscado entre los títulos inscritos en los libros de la Contribución Industrial aquellas cabeceras que se hubiesen mantenido en activo durante los mismos años de El Campo, una característica complicada ya que durante el XIX rara era la cabecera que mantenía su publicación durante un periodo largo de tiempo. De entre las seleccionadas en esta primera fase se ha realizado una segunda distinción por área temática, y la muestra ha quedado reducida a: dos cabeceras dedicadas a la moda (La Moda Elegante y El Correo de la Moda), dos humorísticas (Madrid Cómico y Mundo Cómico), una política-cultural (La Ilustración Española y Americana) y finalmente El Campo como ejemplo de prensa de ocio.

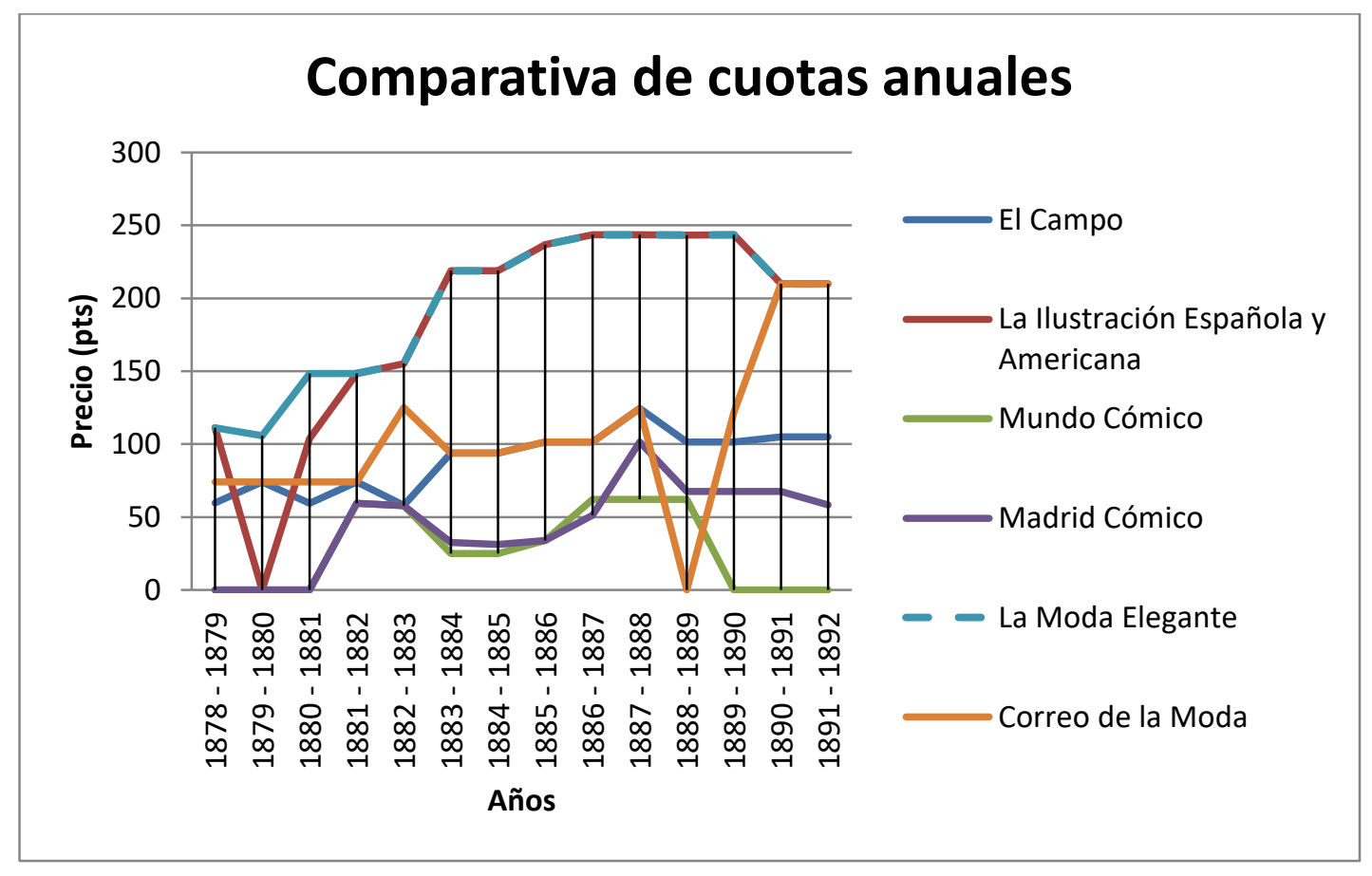

Comparativa de la evolución de las cuotas anuales de varias publicaciones catalogadas como prensa científica entre los años 1878 a 1892. Datos obteridos de los libros de la Contribución Industrial del 9047 al 9077, Fondo 1, Ministerio de Hacienda, AGA. Elaboración propia.

A raíz de la gráfica podemos destacar varios puntos; por un lado, que a pesar de encontrar cabeceras de una misma área temática su cuota es variable. Tanto el Correo de la Moda como La Moda Elegante eran publicaciones semanales, con una media de diez páginas por ejemplar, ambas incorporaban grabados e ilustraciones coleccionables como gancho para el público femenino; no obstante, a pesar de estas coincidencias, la cuota de La Moda Elegante fue siempre superior a la del El Correo de la Moda. Al contrario que en el caso de la moda, la prensa satírica mantuvo un mismo nivel de cuotas, es más, se observan los cambios en las cuotas se reflejan en ambas publicaciones, tanto si desciende como aumenta queda reflejado en ambas cabeceras. Para terminar, mientras que la mayoría de publicaciones analizadas sufren una serie de 
altibajos dentro del precio de sus cuotas, tanto La llustración Española y Americana, como La Moda Elegante y El Campo sufrieron un incremento paulatino de su cuota desde principios de los 80 hasta la década de los 90, cuando el precio de la cuota desciende en los dos primeros casos, y se mantiene prácticamente igual para la cabecera dedicada al sport.

El Campo se encontraba entre los cuatro "periódicos científicos" que más cuota debían pagar anualmente. Salvo esta cabecera todos eran de periodicidad semanal. ¿Qué ocurría? O bien los periódicos dirigidos por Abelardo de Carlos tenían una cuota mayor de la habitual en un periódico de sus características, o bien las publicaciones satíricas y El Correo de la Moda, todas ellas también de periodicidad semanal, tenían una cuota mucho menor ¿Qué ocurre si se incorpora un dato nuevo a esta ecuación? Al comparar la cuota a pagar en relación al precio que imponían cada publicación a sus lectores, queda establecido que aquellas publicaciones con mayor precio en su venta también eran las que tenían una cuota anual más alta. Si hablamos en términos trimestrales, desde mediados de los 70 y durante toda la década de 1880, La Ilustración Española y Americana cobraba a sus suscriptores 10 pesetas, El Campo 6 pesetas, Mundo Cómico y Madrid Cómico 3 y 2,5 respectivamente. ${ }^{6}$ Las cifras revelan cierto conocimiento por parte del gobierno sobre a qué publicación podía pedir más o menos cuota en función del precio de su venta; de este modo, aunque había publicaciones con una periodicidad similar, que a priori parecía ser la característica a partir de la cual se marcaba la cuota, finalmente el impuesto variaba en función de las ganancias que podía obtener las cabeceras periodísticas por el precio de su suscripción.

Estos datos sólo reflejan una pequeña porción de la tarta periodística; sería enriquecedor mezclar estas primeras observaciones con la información obtenida al analizar el resto de los sectores que quedaron reflejados en la Contribución Industrial. Como un pequeño ejemplo, durante el mismo periodo analizado en las anteriores cabeceras, dos publicaciones satíricas Gil Blas y El Motín fueron clasificadas en la contribución industrial como "periódicos políticos" y se les fijó una cuota anual de más de 200 pesetas, al nivel de La Ilustración Española y Americana, la gran diferencia reside en que mientras la publicación de Abelardo de Carlos cobraba 10 pesetas cada tres meses a sus suscriptores, el precio de Gil Blas y de El Motín era de 4 y 2,50 pesetas respectivamente; los ingresos de las cabeceras humorísticas eran mucho menores y de ahí que vuelva a ser destacable la figura del gobernador civil y su interés porque una publicación u otra pudiera seguir publicándose.

\footnotetext{
${ }^{6}$ Las publicaciones de moda no publicaban el precio de su suscripción por lo que ha sido imposible analizar estas cabeceras en función del precio de su venta.
} 


\begin{tabular}{|c|c|c|c|c|}
\hline Cabecera & Periodicidad & $\begin{array}{l}\text { Categoría } \\
\text { Contribución } \\
\text { Industrial }\end{array}$ & $\begin{array}{l}\text { Cuota media } \\
\text { Contribución } \\
\text { Industrial } \\
\text { (pts) }\end{array}$ & $\begin{array}{l}\text { Precio } \\
\text { suscripción } 3 \\
\text { meses (pts) }\end{array}$ \\
\hline $\begin{array}{l}\text { La Ilustración Española } \\
\text { y Americana }\end{array}$ & Semanal & $\begin{array}{l}\text { Prensa } \\
\text { científica }\end{array}$ & 213,5 & 10 \\
\hline Mundo Cómico & Semanal & $\begin{array}{l}\text { Prensa } \\
\text { científica }\end{array}$ & 48,4 & 3 \\
\hline Madrid Cómico & Semanal & $\begin{array}{l}\text { Prensa } \\
\text { científica }\end{array}$ & 54,4 & 2,5 \\
\hline El Motín & Semanal & $\begin{array}{l}\text { Prensa } \\
\text { política }\end{array}$ & 146,9 & 2,5 \\
\hline Gil Blas & Bisemanal & $\begin{array}{l}\text { Prensa } \\
\text { política }\end{array}$ & 225,9 & 4 \\
\hline
\end{tabular}

Esta investigación ha dado protagonismo a El Campo para equiparar su desarrollo con el de otros títulos que se encontraban dentro de su misma categoría. Si incluimos en el estudio a las publicaciones satíricas llamaría nuestra atención el gran número de publicaciones joco-serias inventariadas en el apartado político incrementando sus cuotas considerablemente en comparación a las cabeceras humorísticas catalogadas en "prensa científica". Así, se vuelve a retomar la idea expresada por Guadalupe Aguado del interés por parte de los poderes políticos de incluir los títulos satíricos dentro del apartado político y obligarles a pagar una mayor cuota. Una de las funciones de esta figura gubernamental era el control fiscal sobre las publicaciones, «la contribución industrial -puesta en marcha en 1849- se convirtió en una fuerte sangría para la prensa, especialmente para aquella de carácter político » ${ }^{7}$; no sólo se trataba de censura, había otra clase de muros que podían influir en la publicación o no de una revista y así aparece reflejado en estos datos entremezclados, si una publicación era categorizada dentro de la prensa política en vez de en la científica su cuota anual aumentaba automáticamente y eso dificultaba su continuidad. Es interesante observar

\footnotetext{
${ }^{7}$ María José RUIZ ACOSTA: “Poder político y prensa: la figura del gobernador civil en el sistema informativo de la España decimonónico", Revista de historia contemporánea, 9 (1999 - 2000), pp. 25-36.
} 
que el humor era visto como una herramienta en la difusión de ideas políticas y a pesar de no utilizar un lenguaje político como podía encontrarse en La Correspondencia de España, El Imparcial o El liberal las cabeceras joco-serias eran entendidas como prensa que difundía ideología política. Así, aunque presenten características similares a las incluidas en "prensa científica": publicaciones semanales o bisemanales, ilustradas, con noticias culturales sobre teatro o literatura finalmente eran categorizadas dentro de la sección de publicación política.

\section{Conclusiones}

Las publicaciones periódicas forman parte de la formación de esa cultura de masas que inició su andadura a finales del XVIII y durante todo el XX. Para profundizar en su desarrollo se debe incidir en el estudio de los productos culturales propios de cada época, y sin dudarlo la prensa era y sigue siendo uno de los más relevantes. Para conseguir un estudio en profundidad de la cultura de masas y su vinculación con el mundo periodístico es necesario una revisión dentro de la propia historia de la prensa; dejar a un lado los trabajos dedicados a la categorización de las cabeceras, en los que principalmente se enumeran: los directores, el número de página, el número de ejemplares, etc. Adentrarnos en la formación de los periódicos: quién los fundaba, por qué, cuál es su sustento y su difusión utilizando más datos que los ya conocidos por los archivos del Timbre. Por ello, veo necesario introducir en el estudio de la prensa información proporcionada por los archivos de Comercio o de Hacienda.

Centrándonos en la evolución de El Campo en relación con las otras cabeceras analizadas, se observa cómo esta publicación mantuvo su estatus dentro de la prensa especializada con una suscripción fija para sus lectores; lo que a su vez repercutió en la cuota establecida en la Contribución Industrial. Lo mismo le ocurrió a la cabecera $L a$ Ilustración Española y Americana, de gran popularidad entre la burguesía española, podemos intuir que al igual que la publicación de Abelardo de Carlos mantuvo un grado de popularidad y repercusión en la prensa, en el caso de El Campo pudo suceder lo mismo; por desgracia, son pocas las investigaciones que se han centrado en el estudio de la prensa dedicada al sport.

No hay que olvidar que este tipo de investigaciones poseen una gran problemática: la carencia de estadísticas oficiales y la poca fiabilidad de las existentes. Esta ausencia de datos entorpece el estudio de la prensa en sus áreas de difusión y recepción (VIDAL PELAZ, 2000: 169); sin embargo, una recopilación de diversas fuentes puede permitir al historiador ver en profundidad grados empresariales y de difusión periodística que apenas han sido tratados. El trabajo es arduo pero no imposible y así lo han demostrado varios estudios como los realizados por Juan Luis Guereña, Jean-François 
Botrel o Celso Almuiña ; concretamente el último autor utiliza mezcla la información de la Contribución Industrial, el Timbre y de las Libranzas especiales para la prensa con el objetivo de llenar lagunas sobre la difusión de las publicaciones periódicas en Valladolid.

Si se llegase a profundizar en la información sobre la difusión de la prensa, se podrá organizar el mapa periodístico en España durante la segunda mitad del XIX. Sobre la prensa política se conoce algo más, pero llegar a la misma precisión en otros ámbitos como la prensa satírica o la deportiva permitiría comprender esa cultura de masas que se genera paulatinamente durante el XIX, vinculada a cambios sociales y culturales. Una pequeña aproximación se ha intentado realizar en estas páginas aproximándonos a una cabecera poco conocida como El Campo; las cifras analizadas ofrecen las primeras pistas sobre el interés de la sociedad por la información deportiva vinculada al sport proveniente de Inglaterra, una actividad se irá asentando desde mediados del XIX hasta llegar a altos grados de popularidad entre la burguesía española al llegar a finales de siglo. ${ }^{9}$

\footnotetext{
${ }^{8}$ ALMUIÑA FERNÁNDEZ, C. (1980): “Aproximación a la Evolución Cuantitativa de la Prensa Española entre 1868-1930", Investigaciones históricas: Época moderna y contemporánea, №2, 1980, pp.295-343; GUEREÑA, J. L. (1982): “Las estadísticas oficiales de la prensa (1867-1927)", en BARRÈRE, B. (coord.): Metodología de la historia de la prensa española trabajos presentados en el Seminario de Metodología de la Historia de la Prensa Española, Madrid, Siglo XXI.

${ }^{9}$ Para conocer más sobre la evolución deportiva de finales de siglo y su papel social: PUJADAS I MARTI, X. y SANTACANA TORRES, C (2012): "Prensa, deporte y cultura de masas. El papel del periodismo especializado en la expansión social del deporte en Cataluña hasta la guerra civil (1890-1936)", en Historia y comunicación social, nำ17, 2012, pp.141-157.
} 


\section{Fuentes primarias}

Debido al uso que se realiza dentro de este artículo de los datos procedentes de los libros de la Contribución Industrial y al no encontrarse estos con una numeración contínua considero necesario el siguiente cuadro. En sus columnas se especifica la numeración del libro en coorelación con el año al que pertenece. Todos estos libros registran los datos de la contribución industrial referentes a las cabeceras catalogadas como "periódicos políticos" y "periódicos científicos".

\begin{tabular}{|c|c|}
\hline Numeración & Años \\
\hline 9047 & $1877-1878$ \\
\hline 9048 & $1878-1879$ \\
\hline 9426 & $1879-1880$ \\
\hline 9427 & $1880-1881$ \\
\hline 9428 & $1881-1882$ \\
\hline 9049 & $1881-1882$ \\
\hline 9050 & $1882-1883$ \\
\hline 9052 & $1883-1884$ \\
\hline 9054 & $1884-1885$ \\
\hline 9057 & $1885-1886$ \\
\hline 9060 & Adiciones de 1885 - 1886 \\
\hline 9062 & $1886-1887$ \\
\hline 9063 & Adiciones $1886-1887$ \\
\hline 9065 & $1887-1888$ \\
\hline 9066 & Adiciones $1887-1888$ \\
\hline 9067 & $1888-1889$ \\
\hline 9070 & $1889-1890$ \\
\hline 9071 & Adiciones $1889-1890$ \\
\hline 9073 & $1890-1891$ \\
\hline 9074 & Adiciones 1890 - 1891 \\
\hline 9075 & $1891-1892$ \\
\hline 9077 & $1891-1892$ \\
\hline
\end{tabular}




\section{Referencias bibliográficas}

AGUADO, G. (1995): Verificación de la difusión de prensa en España, Tesis doctoral, Universidad Complutense de Madrid.

ALMUIÑA FERNANDEZ, C. (1977): La prensa Vallisoletana durante el siglo XIX (18081894), Valladolid, Instituto Cultural Simancas.

- (1980): “Aproximación a la Evolución Cuantitativa de la Prensa Española entre 1868-1930", Investigaciones históricas: Época moderna y contemporánea, nํ2, 1980, pp.295-343.

ANÓNIMO: "Newmarket", en El Campo: agriculura, jardinería y sport, n24, 16-11$1877, \sin p$.

BOTREL, J. F. (1975): "Estadística de la prensa madrileña de 1858 a 1909 según el Registro de Contribución Industrial”, en TUÑóN DE LARA, M., ELORZA, A. y PÉREZ LEDESMA, M. (editores): Prensa y sociedad en España (1820-1936), Madrid, Edicusa, pp. 25-46.

- (1993): Libros, prensa y lectura en la España del siglo XIX, Madrid, Fundación Germán Sánchez Ruipérez.

CAZOTTES, G. y RUBIO CREMADES, E. (2012): "El auge de la prensa periódica", Biblioteca Virtual Miguel de Cervantes, 2012. Disponible en internet (16-122016): http://www.cervantesvirtual.com/obra/el-auge-de-la-prensa-periodica/

GUEREÑA, J. L. (1982): "Las estadísticas oficiales de la prensa (1867-1927)", en BARRÈRE, B. (coord.): Metodología de la historia de la prensa española trabajos presentados en el Seminario de Metodología de la Historia de la Prensa Española, Madrid, Siglo XXI.

HIGUERAS CASTAÑERA, E. (2014): “Prensa y partido en el republicanismo progresista: El Porvenir (1882-1885)", Historia Contemporánea, no50, 2014, pp. 41-73.

JOVELLANOS, G. M. (1790): Memoria para el arreglo de la policía de los espectáculos y diversiones públicas y sobre su origen en España, Biblioteca Virtual Miguel de Cervantes. Disponible en internet (10-06-2016): http://www.cervantesvirtual.com/obra/memoria-para-el-arreglo-de-la-policiade-los-espectaculos-y-diversiones-publicas-y-sobre-su-origen-en-espana--0/

MARRAST, R. (1975): "La prensa española del siglo XX: algunos problemas de investigación”, en TUÑóN DE LARA, M., ELORZA, A. y PÉREZ LEDESMA, M. (editores): Prensa y sociedad en España (1820-1936), Madrid, Edicusa, pp. 15-21. 
PIZARROSO QUINTERO, A. (1994): Historia de la Prensa, Madrid, Centro de Estudios Ramón Areces.

SAINZ DE BARANDA ANDÚJAR, C. (2013): “Orígenes de la prensa diaria deportiva: EI Mundo deportivo", en Materiales para la historia del deporte, $\mathrm{n}=11,2013$, pp. 727.

SÁNCHEZ VIGIL, J. (2008): Revistas ilustradas em España. Del Romanticismo a la guerra civil, Gijón, Trea.

SEOANE, M. J. (1983): Historia del periodismo en España. El siglo XIX, Madrid, Alianza Editorial.

TIMOTEO ALVAREZ, J. (1981): Restauración y prensa de masas: los engranajes de un sistema (1875-1883), Pamplona, Ediciones Universida de Navarra.

URÍA GONZÁLEZ, J. (2001): "El nacimiento del ocio contemporáneo", en Historia social, no 41, pp.65-68.

- (2001): "Lugares para el ocio: Espacio público y espacios recreativos en la Restauración española", en Historia social, nำ1, pp.89-112.

VIDAL PELAZ, J. (2000): "Registradores, recaudadores y notarios: Fuentes para la historia de la empresa periodística en España", en Investigaciones históricas: Época moderna y contemporánea, nำ20, pp. 169-182. 